\title{
Transversalización: evaluación de competencias de igualdad de género en la formación de las mujeres militares ${ }^{1}$
}

\author{
https://doi.org/10.21830/9789585318304.03
}

\author{
Edna Jackeline Latorre Rojas ${ }^{2}$ \\ Luis Alberto Isaza Rodríguez ${ }^{3}$ \\ Manuela Mateus Rodriguez ${ }^{4}$ \\ Escuela Militar de Cadetes "General José María Córdova”
}

\section{Resumen}

Este capítulo se propone mostrar la importancia de la evaluación de las competencias de igualdad de género del Programa Académico en Ciencias Militares, frente al desarrollo de los cambios deseables en materia de inclusión del enfoque diferencial en las situaciones académicas del contexto militar. El objetivo central es compartir el modelo de evaluación, basado en un enfoque educativo constructivista, de dichas competencias en las áreas de formación académica del programa. Para tal fin se plantea la importancia de la evaluación de programas académicos para fomentar la transversalización del enfoque diferencial desde procesos académicos. A continuación, se presenta la fundamentación del modelo de evaluación del programa y finalmente se muestran los resultados de la evaluación. El estudio se desarrolló a partir de una metodología

1 Este capítulo presenta los resultados del proyecto de investigación "Propuesta curricular para el fomento de una cultura de equidad en el proceso formativo de los futuros oficiales de la ESMIC" del Grupo de Investigación en Ciencias Militares, de la Escuela Militar de Cadetes "General José María Córdova” (ESMIC), categorizado en B por Minciencias y con código de registro COL0082556. Los puntos de vista y los resultados de este artículo pertenecen a los autores y no reflejan necesariamente los de las instituciones participantes.

2 Magíster en Educación e Investigación Universitaria (Universidad Sergio Arboleda). Especialista en Educación e Investigación Universitaria (Universidad Sergio Arboleda). Psicóloga (Universidad Católica de Colombia). Investigadora del Grupo de Investigación en Ciencias Militares, de la Escuela Militar de Cadetes "General José María Córdova”. Orcid: https://orcid.org/0000-0002-0301-9036 - Contacto: edna.latorre@esmic. edu.co

3 Psicólogo con especialización en Psicología Clínica y Organizacional. Especialista en Análisis Motivacional Aplicado al Comportamiento Humano. Magíster en Resolución de Conflictos y Mediación. Magíster en Dirección Estratégica, con Especialidad en Gerencia y Orientación. Especialista en Pedagogía y Docencia Universitaria. Docente e investigador de la Facultad de Ciencias Militares en la Escuela Militar de Cadetes. Orcid: https://orcid.org/0000-0002-9491-2953 - Contacto: luis.isaza@esmic.edu.co

4 Psicóloga (Universidad Santo Tomás), con profundización en el área de Psicología Clínica. Especialista en Logística Militar. Experiencia en el área de Psicología Militar en el Ejército Nacional de Colombia. Docente e investigadora de la Facultad de Ciencias Militares (ESMIC). Orcid: https://orcid.org/0000-0002-2297-2535 Contacto: manuela.mateus@esmic.edu.co 
cualitativa, cuyo objeto de estudio fueron las propuestas académicas, las propuestas curriculares y el syllabus de las áreas de formación académica del programa.

Palabras clave: ciencias militares; ESMIC; modelo por competencias; procesos académicos; transversalización

\section{Introducción}

Las políticas de inclusión e igualdad de género en las Fuerzas Militares son un tema que cobra importancia para poder dar respuesta a los interrogantes en torno a la equidad entre hombres y mujeres. No obstante, mucho de lo que se escribe sobre perspectiva de género carece de planteamientos epistemológicos sólidos, debidamente fundamentados desde lo teórico y conceptual, para poder, a su vez, generar una producción sólida sobre el tema. Prueba de ello es la concepción de equidad y género de la política pública sectorial de transversalización del enfoque de género para el personal uniformado de la Fuerza del 2018 emitida por el Ministerio de Defensa Nacional, puesto que en ella no se observa una teoría base que sostenga los lineamientos y se adopte como fundamento del enfoque de equidad de género. De esta manera, se evidencia que la primera dificultad es la falta bases teóricas bien establecidas sobre equidad de género para su apropiación en las políticas que regulan la educación en el contexto militar.

Conforme a esta situación, es importante reconocer la educación como uno de los aspectos fundamentales para evitar las desigualdades sociales derivadas del género. Como lo plantea Buxarrais (2008), es a través de ella que las personas pueden descubrir, conocer y reconocer sus recursos personales y lo que, de una manera u otra, ofrecen a los demás a través de la interacción social.

Es por eso que las instituciones de educación superior, específicamente, las escuelas de formación militar, dentro del marco de las políticas de inclusión educativa, están llamadas a gestar procesos académicos que logren impactar la formación de los nuevos profesionales, de acuerdo con las demandas actuales, según dos grandes aspectos de interés: por un lado, la parte legal y administrativa de la educación y, por otro, el análisis reflexivo del proceso educativo, condensado en las políticas académicas para la transversalización de la igualdad y la equidad.

Resulta importante aclarar que la aplicación de las políticas educativas que promuevan la transversalización del enfoque de género en los sistemas educativos genera estados de conmoción al interior de las instituciones, muchas de estas, marcadas por procesos de resistencia al cambio dentro de su cultura. Este fenómeno en ocasiones impide que se regulen las iniciativas para crear, fortalecer e incor- 
porar modelos de evaluación y aprendizaje nuevos e impactantes que garanticen los procesos de mejora en la calidad educativa con enfoque de género.

Por tanto, ocurre que muchas instituciones se oponen a asumir nuevos modelos educativos, puesto que estos demandan una dinámica adaptativa que permita el ajuste de los contextos a nuevas experiencias de aprendizaje; pero como las instituciones no se encuentran capacitadas y listas para cumplir con estas exigencias, los procesos de incursión se hacen lentos y, en ocasiones, poco motivantes.

Por otro lado, existen instituciones que no cuentan con los recursos suficientes para la creación y puesta en marcha de prácticas innovadoras que les permitan ajustar sus procesos educativos para impactar en materia de género y se limitan a hacer los que se les pida con los elementos que tengan, sin generar mayor valor al proceso de formación. Finalmente, hay otras instituciones que simplemente no están interesadas en la transversalización del enfoque de género bajo un modelo pedagógico innovador, de forma que no crean impacto ni nuevas dinámicas de evaluación de sus procesos y programas.

Hasta aquí, se aclara un poco el contexto de la problemática implicada por la asunción modelos educativos innovadores en materia de género en las instituciones de educación superior; sin embargo, es importante centrar este análisis de la problemática en el contexto de la Escuela Militar de Cadetes "General José María Córdova”, de manera específica, en la categoría de estudio "equidad de género entre hombres y mujeres".

En cuanto a esto, la ESMIC cuenta desde su estructura orgánica con el Observatorio de Género, creado en el 2012, como iniciativa para la promoción de la inclusión de la mujer en la vida militar mediante la convocatoria e ingreso en el curso de las armas. En ese momento se da una mirada al rol de la mujer en el Ejército y se comienzan a hacer ajustes en las dinámicas que, desde antaño, habían sido creadas y dirigidas únicamente para hombres. La función del Observatorio de Género era entonces netamente investigativa y buscaba generar un impacto en la comunidad desde lo científico, sin embargo, las acciones de asistencia y promoción de la equidad no fueron suficientes y el Observatorio de Género se limitó a crear pocos proyectos de investigación, responder a estadísticas de incorporación y presentar datos de segregación por sexos, entre otros. Claramente se dejó en un segundo plano la preocupación por las violencias hacia la mujer, el trato desigual, la rivalidad entre sexos y la asignación de roles específicos por sexo. Esto coincidió con el surgimiento de una cultura de esquemas de rivalidad entre hombres y mujeres, que no fueron tomados en cuenta dentro los planteamientos académicos de formación y los currículos de los programas de formación ofertados. En la actualidad, las 
acciones para la promoción de la equidad entre hombres y mujeres en la ESMIC son aisladas, escasas y no logran tener el impacto esperado dentro de la comunidad académica.

En consecuencia, los procesos de evaluación también se ven afectados, ya que se limitan a la obtención de indicadores cuantitativos, tal y como es el caso de las propuestas evaluativas de las áreas de formación académica dentro del PEP, que están lejos de análisis profundos de las competencias de igualdad de género en sus propuestas de formación académica, condensadas específicamente en los syllabus. Esto exige que se piense en equiparar las oportunidades para mujeres y hombres en el contexto militar desde la academia, a raíz de lo cual se plantea el siguiente interrogante: ¿Qué aspectos debe tener una evaluación integral de las competencias de igualdad de género del programa de Ciencias Militares para propiciar la transversalización del enfoque de género en su currículo?

\section{Marco de referencia}

\section{La evaluación de programas académicos como transversalización del enfoque diferencial: mainstreaming}

"La energía creativa de la antropología emana de la tensión entre dos tipos de exigencias: por un lado nos ocupamos de seres humanos universales y, por otro, de realidades culturales particulares" (Stolke, 2004, p. 78); es así como el debate del mundo dicotómico se expresa en términos biológicos y sociales, y la realidad del enfoque de género no está distante de este mundo de oposiciones. Por tanto, no es raro encontrar posiciones a favor y en contra de los estudios de género, frente a las cuales surgen las críticas y las largas defensas, necesarias para comprender un mundo que de alguna manera demanda equidad e igualdad.

En ese contexto, cada día surgen estudios sobre la mujer, se encuentran relatos en los que se promueve su participación activa en los aspectos económicos, políticos y sociales, lo que les permite a las mujeres apropiarse de espacios que por milenios han sido solo de hombres. Con esto se resalta que la postura de este escrito frente al concepto de mujer es humanista, porque se reconoce a la mujer como la mitad de la población y no como el "segundo sexo", tal y como lo expresa Simone de Beauvoir (1949) cuando habla que la opresión de la mujer no se da por factores biológicos, psicológicos o económicos, sino por la relación entre ellos; es así como esta autora critica las posturas en las que "la humanidad es masculina y el hombre define a la mujer no en sí misma, sino en relación con el hombre... Él es el sujeto, él es lo absoluto —ella es la otra” (p. 40, traducción propia). 
Adicional a lo anterior, desde la perspectiva sociológica de Pierre Bourdieu, se plantea la concepción de género de la siguiente manera:

Las apariencias biológicas y los efectos indudablemente reales que ha producido, en los cuerpos y en las mentes, un prolongado trabajo colectivo de socialización de lo biológico y de biologización de lo social, se conjugan para invertir la relación entre las causas y los efectos y hacer aparecer una construcción social naturalizada (los "géneros" en cuanto que hábitos sexuados como el fundamento natural de la división arbitraria que está en el principio de la realidad, como la representación de la realidad que se impone a veces la propia investigación). (Bourdieu, 2000, p. 13)

Lo que desde ya define y divide al género "construcción social” de lo biológico "sexo". Además, Bourdieu hace referencia a la división socialmente impuesta entre los géneros, la necesaria diferencia marcada entre lo femenino y lo masculino como realidad aceptada.

De otro lado, el término transversalización de género, en inglés gender mainstreaming, surge a partir de los análisis, reflexiones y valoraciones realizadas desde los años setenta sobre los procesos de equidad e igualdad entre hombres y mujeres. Es así como la transversalización se convierte en una estrategia de las Naciones Unidas y de los tratados de la Comisión Europea para la promoción de la equidad de género a partir del diseño, la planificación, la implementación y la evaluación de políticas públicas, que van a ser sentadas en las conferencias mundiales sobre la mujer de la ONU, como la IV Conferencia Mundial de la Organización de Naciones Unidad sobre la Mujer de Beijing (1995) .

Es a partir de estos cimientos que se entiende la finalidad de la transversalización de género como un proceso importante, que garantice la legitimidad de los principios de igualdad y equidad desde unos postulados claramente establecidos:

a) incorporación de la perspectiva de género en los procesos de toma de decisiones, b) proyección de los posibles impactos que las diferentes medidas políticas y programas puedan tener sobre los hombres y las mujeres, c) promoción de la equidad de género y la igualdad de oportunidades para hombres como para mujeres, d) empoderamiento femenino, e) cambio estructural de los mecanismos que reproducen las desigualdades, y f) rediseño cultural a través de la implementación, monitoreo y evaluación de políticas y programas que permitan el logro de la equidad y la igualad en la cotidianidad. (Durán, 2012, p. 7)

En este sentido, la transversalización del género tiene una connotación sistémica, en la que se entiende que los ambientes educativos son contextos de encuentro cultural que, según Hoy y Miskel (2014), conforman "sistemas sociales en sí, que poseen diversas características; una de las distintivas se refiere a su aper- 
tura hacia el entorno exterior, lo cual permite la entrada, salida e interacción entre sus diferentes elementos y fenómeno" (p. 99). Por tanto, el enfoque sistémico va a permitir que dentro de la cultura académica se promuevan procesos con una perspectiva humanista e integradora de los diferentes escenarios en los que interactúan hombres y mujeres. De esta forma resulta posible crear relaciones nuevas basadas en la equidad, que permitan cerrar brechas respecto a las problemáticas de género y educación (Surovikina, 2015).

Es importante considerar que la transversalización en ambientes académicos se puede hacer tomando en cuenta los seis componentes que propone Durán (2012) en su estudio acerca del modelo de implementación del enfoque de género en la educación superior. El primer componente es el análisis del modelo pedagógico institucional, en el que deben considerarse los conceptos institucionales de educación, estudiantes, enseñanza-aprendizaje, enfoque y concepciones pedagógicas, de acuerdo con la administración institucional y la docencia. Asimismo, se deben tomar en cuenta los componentes del diseño curricular, los ejes que serán transversales y la caracterización de la población de estudiantes. El segundo componente es el mismo currículo, en especial el currículo oculto, en el que se tendría que incorporar el enfoque de género en los planes y programas de estudio, de forma que se creen cursos específicos con temáticas y contenidos sobre género en todos los niveles de estudio (pregrado, diplomados y posgrado) y en diferentes áreas de conocimiento.

El tercer componente es la investigación. En este se establece como fundamental la actualización y el enriquecimiento de la investigación formal y la investigación formativa, la creación de centros de investigación que se encarguen de generar nuevo conocimiento sobre temas de equidad e igualdad que impacte en la comunidad académica. Así, se hace posible la toma efectiva de decisiones a nivel institucional para promover la gestión del conocimiento respecto al enfoque de género y tener en cuentan la preservación de derechos humanos sin discriminación. El cuarto componente es el material didáctico y la medición pedagógica que regulen la transversalización del enfoque de género, teniendo en cuenta que es indispensable evitar los estereotipos de género. Al respecto Durán (2012) explica:

Deben evitarse los estereotipos de género o de cualquier otra naturaleza. El análisis de la perspectiva general de textos incluye imágenes, ejercicios (mediación), frecuencia de aparición de mujeres y hombres; naturaleza de la apariencia de los caracteres femeninos y masculinos (roles profesionales, por ejemplo); ilustraciones, resultados, lenguaje inclusivo (libre de sexismo), equilibrio de género en actividades de aprendizaje, texto e imágenes. Se requiere evidenciar la presencia y aportes de 
las mujeres equilibradamente, no como situaciones o casos excepcionales o esporádicos, destacando por igual los logros de mujeres y hombres, evitando aquellas frases o expresiones que refuerzan estereotipos de género. Ninguno de los sexos aparecerá mencionado o ilustrado como superior o inferior al otro, evitando representaciones tradicionales. $(\mathrm{p}, 37)$

A partir de lo anterior, se entiende que las didácticas deben ofrecer modelos positivos de mujeres ejerciendo posiciones de decisión o responsabilidad. En el caso del programa de Ciencias Militares, serían mujeres comandantes que representen modelos de personas que toman decisiones y muestran de manera equilibrada el ejercicio de la profesión militar en ambos sexos.

El quinto componente es una evaluación del aprendizaje que garantice el análisis de procesos e impactos (análisis sociodemográficos). Finalmente, el sexto componente es la autoevaluación de unidades académicas periódica. Este tipo de evaluación permitirá una reflexión de la labor académica que incluya aspectos de calidad de la enseñanza. En este caso particular de estudio, la valoración de la transversalización del enfoque de género implica las evaluaciones del número de estudiantes por carrera, la valoración de la igualdad de trato y participación en las aulas (presenciales o virtuales) y la valoración de las graduaciones por carrera (factores que inciden en la incorporación al mercado laboral, el tipo de inserción y su impacto, entre otros).

Así, la propuesta del modelo de implementación hecha por Durán muestra cómo la evaluación educativa es un componente primordial en la transversalización del enfoque de género en las IES. Por tanto, se reconoce que cada institución puede contar con un modelo evaluativo adaptado a sus condiciones y su contexto educativo particular, con el fin de dar respuesta efectiva a las problemáticas de equidad y género dentro de sus currículos.

\section{Modelo de evaluación TSS en el programa de Ciencias Militares}

La misión de la evaluación en la educación tiene como componente principal los procesos de mejora, en los que se toman en cuenta las personas. Allí, persona es cualquier actor del proceso educativo como eje fundamental de la evaluación, que infaliblemente está conectado con el proceso de formación y aprendizaje por un conjunto de acciones educativas (procesos) que construirán la acción educativa dentro de una institución, tal como lo plantea Constenla (2007): "La misión de la evaluación en la educación es ayudar a las personas a aprender más y mejor”.

La palabra evaluar proviene del francés évaluer, que hace referencia a la acción de valoración, apreciación, señalamiento o estimación de algo. Por tanto la evalua- 
ción tiene que ver con procesos en los que se les da una ponderación a diferentes características, ya sea de forma cualitativa o cuantitativa con el fin de llegar a una toma de decisión frente algún aspecto (Latorre, 2017).

Lattuada (2014) destaca las diferentes dimensiones de la evaluación en las instituciones educativas, que finalmente determinarán la calidad, la factibilidad, la pertinencia, la cantidad de los proyectos, los nuevos conocimientos y las diferentes maneras de presentación (actitudes, percepciones y representaciones) de los procesos de educación. Estos procesos, se relacionan con diferentes maneras de hacer la evaluación y de determinar una metodología según los propósitos evaluativos para llegar a la formulación efectiva de resultados en la formación.

En el caso específico de la evaluación de programas, la definición de evaluación tiene como primer exponente a Tyler (1973), quien plantea que esta "es la congruencia entre los objetivos y las operaciones". Este autor considera que el deber de la evaluación es determinar la coherencia entre el trabajo y los objetivos propuestos. Además, la evaluación evidencia hasta dónde se pudieron cumplir los objetivos mediante la ejecución de programas de currículo y enseñanza (Stufflebeam \& Shinkfield, 1987).

Para Stufflebeam y Shinkfield (1987), la evaluación se encuentra orientada hacia el perfeccionamiento, es decir, es un proceso para identificar, obtener y proporcionar información útil y descriptiva acerca del valor y el mérito de las metas, la planificación, la realización y el impacto de un objeto determinado. Esto se hace con el fin de servir de guía para la toma de decisiones, solucionar los problemas de responsabilidad y promover la comprensión de los fenómenos implicados. Su propósito no es demostrar sino perfeccionar el proceso educativo.

Estas ideas están complementadas por las afirmaciones de Scriven (1967), quien plantea la evaluación como una actividad metodológica que consiste simplemente en la recopilación y revisión sistemática del valor o el mérito de las cosas, y subraya que los evaluadores deben ser capaces de llegar a juicios de valor justificables, más que medir cosas o determinar si las metas han sido alcanzadas.

Así, para lograr la evaluación completa del programa, cada uno de los autores anteriores plantea un proceso de evaluación compuesto por diferentes pasos y características que se presentan en la tabla 1. 
Tabla 1. Matriz de procesos de evaluación de programas

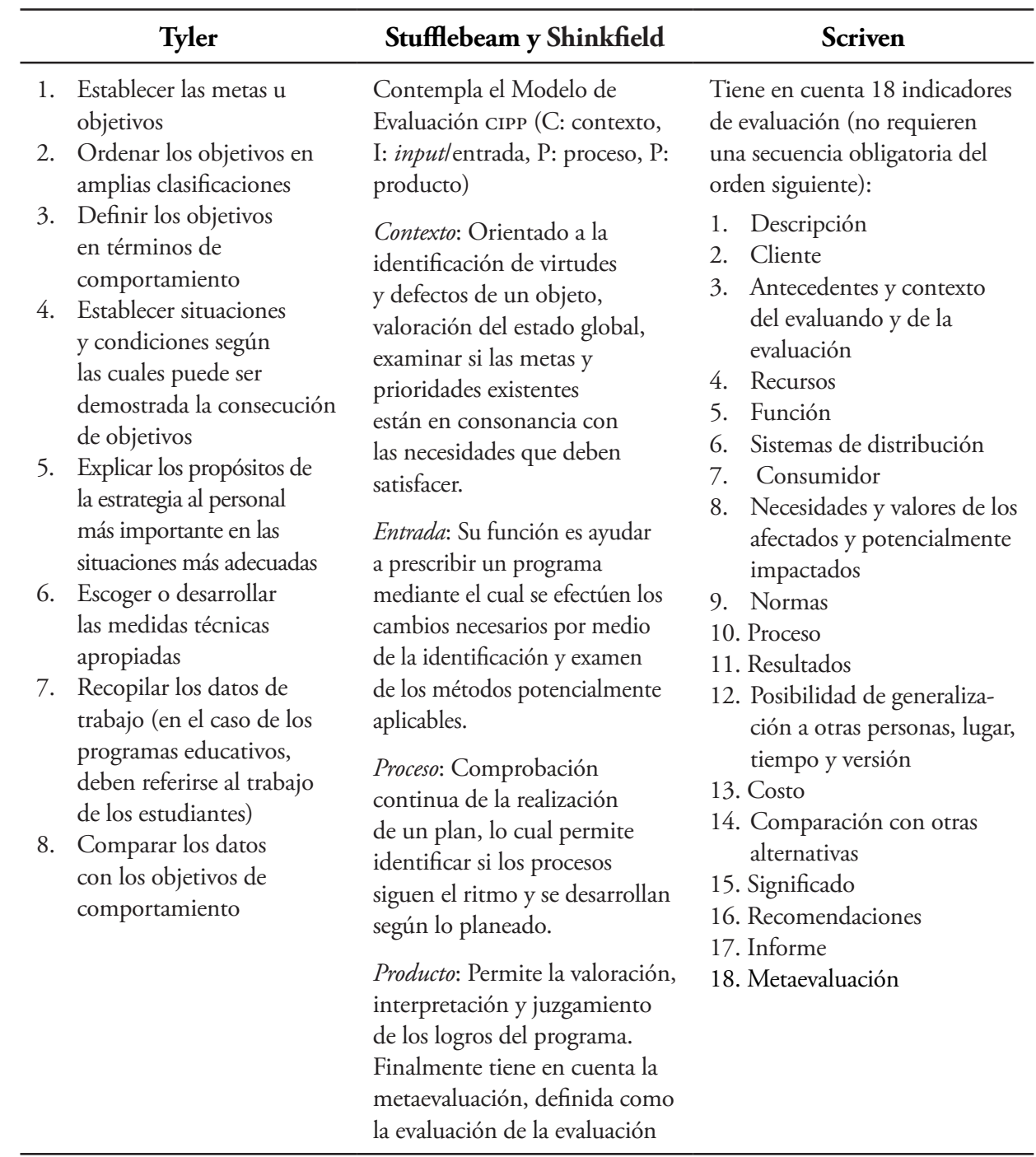

Fuente: Elaboración propia

El análisis de cada uno de los pasos planteados en la tabla 1 permite hacer una síntesis, de acuerdo con la cual se entiende la evaluación como un elemento fundamental para la toma de decisiones para llegar al perfeccionamiento de la educación, incluyendo los propósitos administrativos. Por esta razón, la tabla 1 se propone como guía de aprendizaje y como elemento para el diagnóstico de los objetivos de aprendizaje formulados en los programas académicos, para detectar defectos y 
modificar objetivos, de forma que se satisfagan las posibilidades de aprendizaje y las necesidades del estudiante. Así se espera identificar, obtener y proporcionar información útil y descriptiva acerca del valor y el mérito de las metas, la planificación, la realización y el impacto de un objeto determinado, con el fin de contar con una guía para la toma de decisiones, la resolución de problemas de responsabilidad y la comprensión de los fenómenos implicados. Su propósito, en suma, no es demostrar sino perfeccionar.

La tabla 2 muestra las tres fases que componen el modelo TSS, que surge para evaluar la formación de competencias en condiciones de equidad en diversos contextos, incluidos los contextos educativos para la valoración de competencias de género en el programa de Ciencias Militares. La primera fase es la de implementación, que sugiere crear una ruta evaluativa que tome en cuenta las categorías analíticas de las competencias de género dentro del plan de formación teniendo en cuenta los siguientes componentes: objetivos educativos, contexto, proceso y resultados. La segunda fase es la valorativa, que propone explorar cada una de las características de los componentes del proceso evaluativo a través de las técnicas de recolección de información. La tercera fase concreta la evaluación en un informe final, dividido en cada uno de los componentes que determina los alcances logrados y expone los hallazgos de debilidades y fortalezas del programa de formación.

Tabla 2. Modelo TSS para evaluación de programas en competencias de género

\begin{tabular}{|c|c|c|}
\hline $\begin{array}{c}\text { Fase de } \\
\text { implementación }\end{array}$ & Fase de valoración & Fase de resultados \\
\hline Objetivos & $\begin{array}{l}\text { Definición de los objetivos educa- } \\
\text { tivos. } \\
\text { Establecimiento de situaciones } \\
\text { y condiciones según las cuales se } \\
\text { demuestre la consecución de los } \\
\text { objetivos. }\end{array}$ & $\begin{array}{l}\text { Informe que aclare el plantea- } \\
\text { miento adecuado de los objetivos } \\
\text { educativos y determine si las estra- } \\
\text { tegias que se usaron para alcan- } \\
\text { zarlos fueron efectivas. }\end{array}$ \\
\hline Contexto & $\begin{array}{l}\text { Valoración del estado global de la } \\
\text { institución. } \\
\text { Descripción del contexto, los } \\
\text { antecedentes y personas que inter- } \\
\text { vienen en el proceso de formación. } \\
\text { Determinación de las necesidades, } \\
\text { intereses, valores y exigencias. }\end{array}$ & $\begin{array}{l}\text { Informe que determine si se toman } \\
\text { en cuenta todos los factores del } \\
\text { contexto (antecedentes, necesi- } \\
\text { dades, intereses y exigencias) en la } \\
\text { formación. }\end{array}$ \\
\hline
\end{tabular}




\begin{tabular}{lll}
\hline $\begin{array}{c}\text { Fase de } \\
\text { implementación }\end{array}$ & \multicolumn{1}{c}{ Fase de valoración } & \multicolumn{1}{c}{ Fase de resultados } \\
\hline & $\begin{array}{l}\text { Descripción de actividades, } \\
\text { métodos, estrategias y técnicas apli- } \\
\text { cables al proceso de formación. } \\
\text { Determinación de recursos. } \\
\text { Elaboración de un plan de conse- } \\
\text { cución. }\end{array}$ & $\begin{array}{l}\text { Informe que contraste las estrate- } \\
\text { gias educativas incluidas en el plan } \\
\text { y su sistema de control y ejecución. }\end{array}$ \\
& $\begin{array}{l}\text { Estrategia de control permanente } \\
\text { de la ejecución del plan. }\end{array}$ & \\
\hline & $\begin{array}{l}\text { Logros alcanzados } \\
\text { Evaluación } \\
\text { Informes } \\
\text { Intercambio de experiencias }\end{array}$ & $\begin{array}{l}\text { Informe que confirme la presencia } \\
\text { de productos y la consecución } \\
\text { adecuada de los procesos. }\end{array}$ \\
& Metaevaluación & \\
\hline
\end{tabular}

Fuente: Elaboración propia

Modelo de Formación militar: el Programa de Ciencias Militares

El presente estudio se hizo en la Escuela Militar de Cadetes “General José María Córdova”, institución educativa de enseñanza superior de carácter público, que se encuentra regulada dentro del ámbito administrativo y político por el Ministerio de Defensa y el Ministerio de Educación Nacional. Por lo tanto, estas dos entidades son las responsables de controlar y fomentar los procesos de participación de la ESMIC dentro del marco de las políticas estales que regulan los procesos educativos y, específicamente, la educación en las Fuerzas Armadas de Colombia.

Por su parte, la Facultad de Ciencias Militares es la encargada a nivel nacional de formar y graduar a todos los oficiales de la república que obtienen su título como profesionales en Ciencias Militares. Este es el único programa que se encuentra reconocido ante el Ministerio de Educación Nacional para la formación de oficiales en el país y que, además, cuenta con registro de alta calidad otorgado por el Centro Nacional de Acreditación.

La incorporación de las mujeres dentro del programa académico de Ciencias Militares se hace en el año 2009, cuando se matriculan 62 cadetes femeninas. Es importante decir aquí que el modelo de formación profesional que imparte el programa no presenta ninguna diferencia entre mujeres y hombres.

La gestión educativa de la ESMIC, a través del establecimiento de programas académicos y currículos, promueve el valor de la igualdad, ya que no disgrega la población por ninguna condición y permite que la formación militar sea la misma tanto para 
mujeres como para hombres durante los ocho semestres académicos..$^{5}$ (Fernández \& Latorre, 2018, p. 20)

Dentro del ámbito de ordenación del sistema educativo, se reconoce a través del Proyecto Educativo del programa profesional en Ciencias Militares (en adelante, PEP) que su estructura cuenta con cuatro años de formación, en los que se desarrollan en el estudiante las competencias del ser y convivir, y del saber y el hacer. Dentro del programa, se encuentran las áreas de formación encargadas de garantizar el proceso educativo en lo académico y lo militar de los futuros profesionales. Estas áreas básicamente son cuatro: formación sociohumanística, formación investigativa, formación profesional (que se subdivide en área profesional general y área profesional específica) y formación básica. Tales áreas interrelacionan saberes teóricos, prácticos y actitudinales, con el fin de crear condiciones en el desarrollo de las competencias propuestas para el perfil profesional en Ciencias Militares (ESMIC, 2015)

Respecto a la formación por competencias en los estudiantes (mujeres y hombres), se estructuran curricularmente diferentes áreas de conocimiento como se muestra en la figura 1 .

La práctica educativa está "configurada por profesores y alumnos, básicamente circunscrita a las instituciones escolares lo que comúnmente se llama enseñanza como proceso en el que se comunican y se hacen realidad las propuestas curriculares" (Escorcia et al., p. 65). Así, este sistema de formación propone un puente entre los actores del proceso y las determinaciones sociales que se encuentran dentro del contenido fundamental del proceso educativo, es decir, las experiencias. Para ello, la Facultad de Ciencias Militares toma como base los planteamientos regulados por el Ministerio de Defensa a través del Proyecto Educativo para las Fuerzas Armadas (PEFA) (Ministerio de Defensa Nacional, 2010), en donde se encuentran los lineamientos particulares de los modelos pedagógicos para la formación militar en Colombia y se hace énfasis principalmente en la formación por competencias.

Por tanto, para las Fuerzas Militares de Colombia se señala en los lineamientos del Sistema de Educación de las Fuerzas Armadas que

las competencias se definen como elementos que integran aspectos que tienen que ver con principios, valores, virtudes militares y conocimientos; habilidades y destrezas; actitudes y comportamientos; es decir, abarca aspectos de tipo ético, cognitivo, procedimental y actitudinal, interrelacionados en la búsqueda de un desem-

5 Conclusiones extraídas del documento del proyecto investigación "Caracterización sociodemográfica de los estudiantes de la Escuela Militar en el año 2019”. 


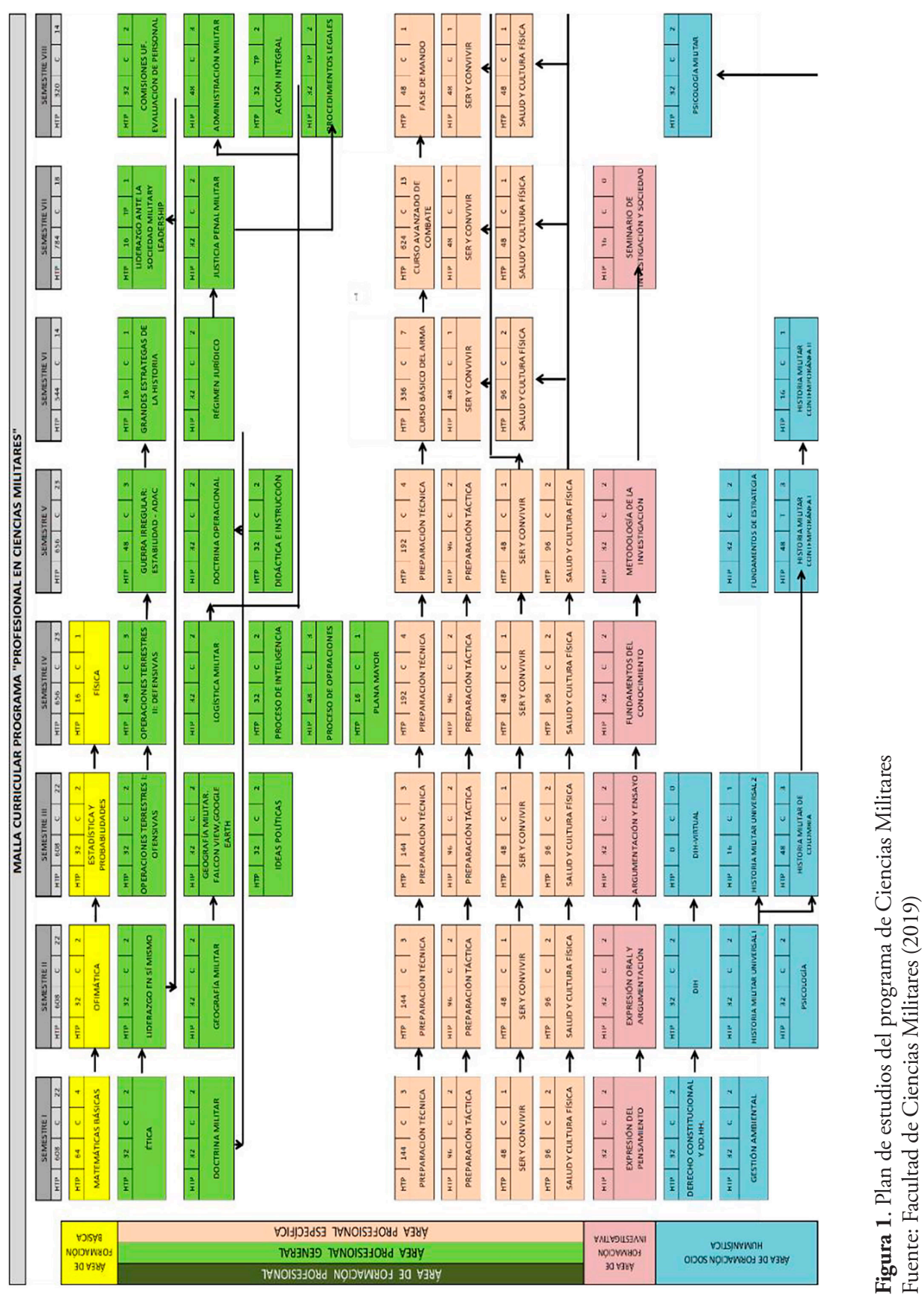


peño eficiente en entornos relacionados con la profesión militar. De esta perspectiva la competencia es integral e integradora. (Ministerio de Defensa, 2010, p. 26)

A raíz de esto, se comienza a hablar de las competencias desde una perspectiva humanista, puesto que estas caracterizan a las personas que están en permanente construcción y transformación, y se manifiestan cuando el ser humano resuelve problemas para su particular realización. La Escuela Militar de Cadetes "General José María Córdova”, siguiendo estos lineamientos, definió unas competencias genéricas y específicas que conciernen a las dimensiones del ser, saber, hacer y convivir (Escuela Militar de Cadetes “General José María Córdova”, 2015).

\section{COMPETENCIAS DE GÉNERo EN LOS PROGRAMAS ACADÉMICOS}

Si bien resulta ardua la tarea de reconocer socialmente el enfoque de género en la actualidad, sobre todo en países latinoamericanos, es aún más difícil lograr su transversalización en los programas académicos de las instituciones educativas en todo nivel. Sin embargo, existen estudios en los que se aborda la temática (Bas-Peña et al., 2017; Asián et al., 2014; Fernández \& Latorre, 2018; Bergold et al., 2017), dentro de los cuales se define la importancia de incorporar materias en los programas académicos sobre género y derechos humanos, y también se resalta la transversalización a partir del uso de textos, lenguaje, imágenes y redes sociales para la consecución de una educación igualitaria que garantice los principios de equidad y respeto.

Uno de los enfoque teóricos que explica la incorporación de las competencias de género en entornos institucionales y académicos es la teoría de aprendizaje social de Vygotsky, de acuerdo con la cual la mediación semiótica del lenguaje comienza a dar respuesta a las interacciones sociales y culturales entre hombres y mujeres. La identidad femenina y masculina se construye en interacción entre los individuos y la sociedad, en diálogo continuo, y se mantiene en constante renovación (Colás, 2007). Es, por tanto, el resultado de la interconexión de los factores sociales (plano interpsicológico) y de los factores personales/subjetivos (plano intrapsicológico). La relación entre estos dos planos se lleva a cabo a través de dos procesos: internalización y apropiación. En el proceso de internalización se desarrollan procedimientos de acción del sujeto mediados por instrumentos culturales (acción mediada). Estos procedimientos son dominar y apropiar — herramientas culturales - y privilegiar y reintegrar (agenciar) — formas de acción dentro de los procesos de interacción(Mimbrero, 2014).

A través de la apropiación, las personas toman algo que pertenece a otros individuos. De esta forma, las herramientas culturales propias de una cultura son 
asumidas por los sujetos estructurando nuevas maneras de interpretar la realidad (Colás, 2007). Este proceso se puede observar cuando mujeres emprendedoras buscan asesoramiento en otras empresarias para poner en marcha capacidades vinculadas al liderazgo cooperativo más representado por el género femenino. El dominio hace referencia al grado de uso que las personas hacen de las herramientas sociales o pautas culturales en distintos contextos (Wertsch, 1991). Tal es el caso de las acciones llevadas a cabo por mujeres y hombres porque les han sido asignadas culturalmente por cuestiones de género.

Esta investigación se apoya en la propuesta de Bunk (1994) sobre las competencias de acción, adaptando su significado al plano de las capacidades de acción de hombres y mujeres para la transformación o mantenimiento de la cultura de género. Un marco que se enlaza con la teoría de aprendizaje social para explicar los procesos de inclusión y transversalización, y a partir de este enfoque, se entiende que la identidad femenina y masculina se construye en interacción entre los individuos y la sociedad, en diálogo continuo y se mantiene en constante renovación (Colás, 2007). De esta manera, se conforma una matriz en la que se encuentran los tres planos distribuidos en las dimensiones de las competencias y los indicadores de cada una de ellas (tabla 3). Estas finalmente se evalúan teniendo en cuenta su componente de representación ${ }^{6}$ en los syllabus y las propuestas académicas por áreas de formación.

6 En este estudio se entiende que un componente social de una representación lo enfatiza básicamente su función, es decir, "proviene de su contribución al proceso de formación de las conductas y de orientación de las comunicaciones sociales" (Araya, 2002, p. 31). Por tanto, son conductas compartidas por varias personas que tienen como características las condiciones de producción de donde emergen (comunicación, interacción y lenguaje) y el desarrollo de una identidad personal y social que busca generar un conocimiento de sentido común. 
Tabla 3. Clasificación de las competencias de igualdad de género

\begin{tabular}{|c|c|c|}
\hline \multirow{2}{*}{ 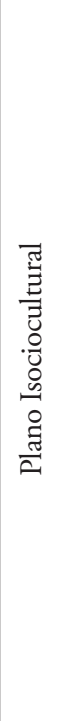 } & $\begin{array}{l}\text { C1. Competencias } \\
\text { de conocimientos } \\
\text { en materia de género } \\
\text { (saber) }\end{array}$ & $\begin{array}{l}\text { - Conocer materias de aprendizaje relacionadas con la aplicación } \\
\text { del enfoque de género. } \\
\text { - Identificar y saber utilizar herramientas para la aplicación de la } \\
\text { transversalidad de género. } \\
\text { - Reconocer las situaciones que viven mujeres y hombres en } \\
\text { distintos escenarios culturales. } \\
\text { - Valorar positivamente las propuestas orientadas a combatir los } \\
\text { desequilibrios existentes entre mujeres y hombres. }\end{array}$ \\
\hline & $\begin{array}{l}\text { C2. Competencias } \\
\text { Metodólogicas } \\
\text { (Saber hacer) }\end{array}$ & $\begin{array}{l}\text { - Contextualizar el uso de conocimientos adquiridos a situa- } \\
\text { ciones reales en las que interactuan hombres y mujeres de la } \\
\text { organización. } \\
\text { - Proponer medidas orientadas a eliminar los modelos tradicio- } \\
\text { nales genéricos (femenino y masculino) que puedan observarse } \\
\text { en la organización. } \\
\text { - Plantear soliciones para superar desequilibrios de género exis- } \\
\text { tentes en la organización. } \\
\text { - Extrapolar actitudes que favorecen la igualdad de género a otros } \\
\text { sistemas de la organización. }\end{array}$ \\
\hline 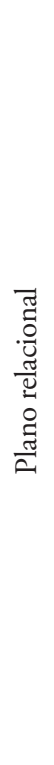 & $\begin{array}{l}\text { C3. Competencias } \\
\text { de participación } \\
\text { (Saber estar) }\end{array}$ & $\begin{array}{l}\text { - Superar resistancias emocionales que subjetivamente aparecen } \\
\text { cuando se accede alconocimiento desde una perspectiva femi- } \\
\text { nista. } \\
\text { - Asumir modelos genéricos construidos en contextos deter- } \\
\text { minados (organización laboral, sistemas familiar...) para } \\
\text { comprender, adaptarse, enfrentarse o resolver situaciones de } \\
\text { desigualdad entre hombres y mujer en distintos escenarios } \\
\text { sociales. } \\
\text { - Poner en marcha actitudes sensiblizadas (que pueden ser adqui- } \\
\text { ridasen otros sietemas y propias del género contrario), inter- } \\
\text { viniendo en la organización para corregir las inequidades de } \\
\text { género. } \\
\text { - Buscar soluciones conjuntas (interrelación con otras y otros } \\
\text { miembros) con objeto de resolver los desequilibrios de género en } \\
\text { la organización. } \\
\text { - Aportar e impulsar propuesta pro igualdad de género a otras } \\
\text { áreas de la organización y/o a otros escenarios culturales. } \\
\text { - Participar como agente activo en iniciativas para la igualdad de } \\
\text { género que emergen en los distintos sistemas en los que inte- } \\
\text { ractúa el sujeto. }\end{array}$ \\
\hline 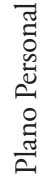 & $\begin{array}{l}\text { C4. Competencias } \\
\text { Personales } \\
\text { (saber ser) }\end{array}$ & $\begin{array}{l}\text { - Reconocer un cambio actitudinal y profesional propio vinculado a } \\
\text { la integración del enfoque de género en el que hacer diario. } \\
\text { - Observar cambios en el reconocimiento de la propia imagen } \\
\text { personal alejado de esencialismos genéricos. }\end{array}$ \\
\hline
\end{tabular}

Fuente: Mimbrero (2014) 


\section{Método para la evaluación con el modelo integrado TSS}

El modelo TSS hace referencia al resultado de la triangulación de los aspectos evaluativos en las propuestas de Tyler, Stufflebeam y Shinkfield, y Scriven. En dicha triangulación se condensan los aspectos concretos de las tres perspectivas para el análisis de las competencias de género de la institución. El proceso de diagnóstico de la investigación se encuentra dentro del marco metodológico como la etapa que utiliza dos técnicas de recolección de información: escala de evaluación y entrevista semiestructurada. El trabajo en las entrevistas se realizó con los cuatro docentes coordinadores de las áreas de formación del programa de Ciencias Militares (Área de Formación Básica, Área de Formación Profesional General, Área de Formación Investigativa y Área de Formación Sociohumanística), quienes son responsables del planteamiento y formación de los componentes académicos y curriculares de los saberes que componen cada una de las áreas. La recolección de información centró su interés en el debate de las categorías de evaluación del modelo TSS mostradas la tabla 2 (objetivos del programa, contexto, proceso y resultado).

El otro instrumento de recolección de datos es una escala de evaluación de competencias de igualdad de género tipo Likert, con 16 ítems correspondientes a cada uno de los indicadores de las competencias tomadas de Mimbrero (2014), en la que se determinan tres niveles de evaluación (baja, media y alta). La validación de contenido del instrumento fue realizada por tres jueces expertos en enfoque de género, a partir del contraste documental del trabajo previo. La validez se determinó a través del análisis de ítems en el programa Ministeps, que arrojó un valor de 0,78 , lo que indica que el instrumento tiene la construcción adecuada para medir las competencias de género en el programa académico de Ciencias Militares. La población utilizada para aplicar esta matriz fue la totalidad de los 45 saberes que conforman el programa de Ciencias Militares.

Así, las fases procedimentales del estudio estuvieron integradas por los siguientes elementos: 1) Diseño y alistamiento de los instrumentos de recolección de información; 2) Recolección de la información: cuatro entrevistas a los coordinadores de áreas y análisis de los 45 syllabus de cada uno de los saberes. 3) Análisis estadístico de la información recolectada. 4) Valoración de acuerdo al modelo TSS. 


\section{Resultados}

\section{La representación de las competencias de igualdad de género en los syllabus de las materias del programa}

Los resultados que se presentan a continuación corresponden al análisis estadístico de la escala de evaluación de competencias de igualdad de género. La representación de estas competencias de manera intrínseca se exploró dentro de los 45 syllabus, es decir, dentro de las competencias específicas en las dimensiones del ser, el hacer, el saber y el convivir de cada una de las materias.

Dentro del Área de Formación General se encuentran las siguientes materias: Ética, Doctrina Militar, Liderazgo en Sí Mismo, Geografía Militar, Falcón View, Google Earth, Logística Militar, Procesos de Inteligencia, Procesos de Operaciones, Plana Mayor, Doctrina Operacional, Didáctica e Instrucción, Régimen Jurídico, Justicia Penal Militar, Administración Militar, Acción Integral y Procedimientos Penales. Los datos de la figura 2 muestran que las competencias de género en esta área se distribuyen de manera homogénea y se inclinan hacia el nivel bajo en las cuatro dimensiones. Sobresale en estos datos el nivel alto, que se observa en las dimensión del saber, es decir, en los conocimientos en materia de género dentro del área. Esto indica que los syllabus de estas materias presentan contenidos conceptuales y teóricos referentes a la igualdad de género.

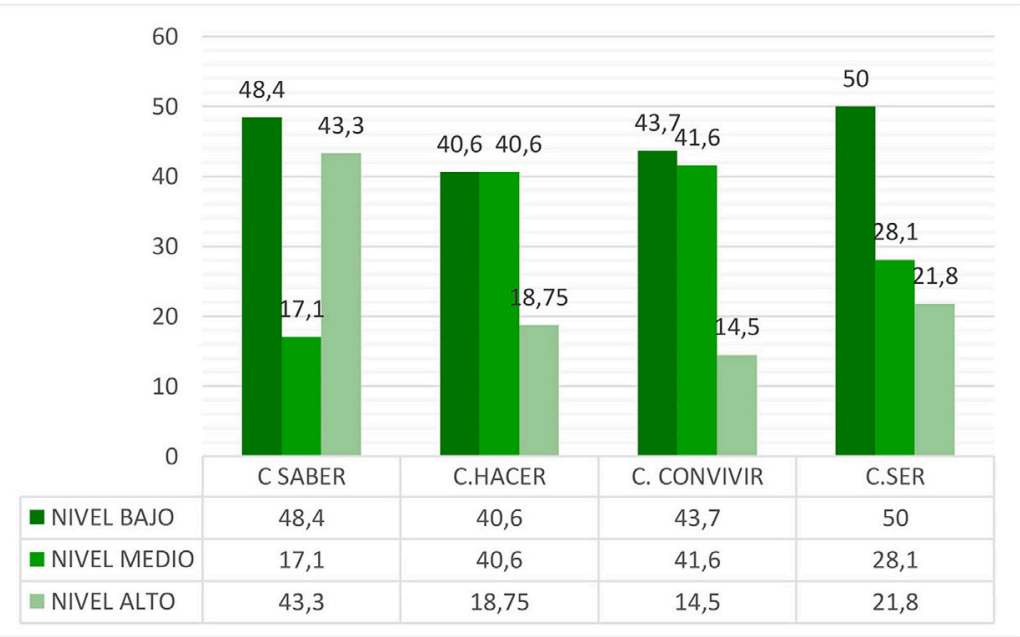

Figura 2. Competencias de igualdad de género en el Área de Formación Profesional General Fuente: Elaboración propia 


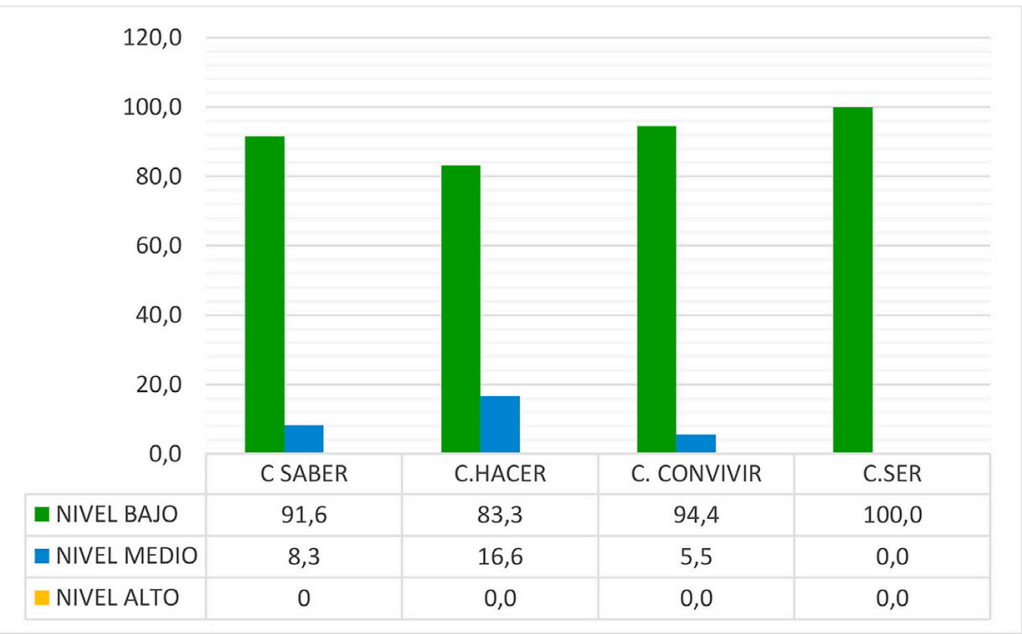

Figura 3. Competencias de género en el Área de Formación Profesional Básica Fuente: Elaboración propia

Las materias que conforman el Área Básica son Matemáticas Básicas, Ofimática, Estadística y Probabilidades, y Física. La presencia de las competencias de género en los syllabus de estas materias se observan en la figura 3. Se puede ver que los datos arrojan un nivel bajo y medio en las dimensiones de las competencias, por lo cual son homogéneos e indicando que las materias no muestran una representación de las competencias de igualdad de género en ninguna de sus dimensiones. Esto resalta el nivel bajo en la dimensión del ser e indican que, en el dominio personal, las actitudes personales y profesionales no son fortalecidas por la incorporación de la igualdad y el género como un condición de estructura del desarrollo humano individual.

El Área de Formación Investigativa está compuesta por las materias Expresión del Pensamiento, Expresión Oral y Argumentación, Argumentación y Ensayo, Fundamentos del Conocimiento, Metodología de Investigación, y Seminario de Investigación y Sociedad. Los datos indican que esta área de formación implementa dentro de sus syllabus las competencias de género en un nivel medio. Se observa, así, una distribución paralela en las dimensiones del ser y en las dimensiones del convivir y el hacer. Se resalta, por tanto, un nivel alto en lo que tiene que ver con lo relacional y lo participativo (figura 4).

La figura 5 muestra la presencia de las competencias de género en el Área de Formación Sociohumanística. Las materias que conforman esta área son Derecho Constitucional y Derechos Humanos (DD. HH.), Derecho Internacional 
Humanitario (DIH), Gestión Ambiental, Historia Militar Universal 1, Psicología, DIH Virtual, Historia Militar Universal 2, Historia Militar de Colombia, Fundamentos de Estrategia, Historia Militar Contemporánea 1, Historia Militar Contemporánea 2. A partir de los datos se puede evidenciar que la presencia de las competencias de género dentro de las cuatro dimensiones es alta y media. Sobresalen específicamente el ser y el saber, lo que indica que en el plano personal y de conocimientos el área fomenta desde sus syllabus la transversalización del enfoque de género.

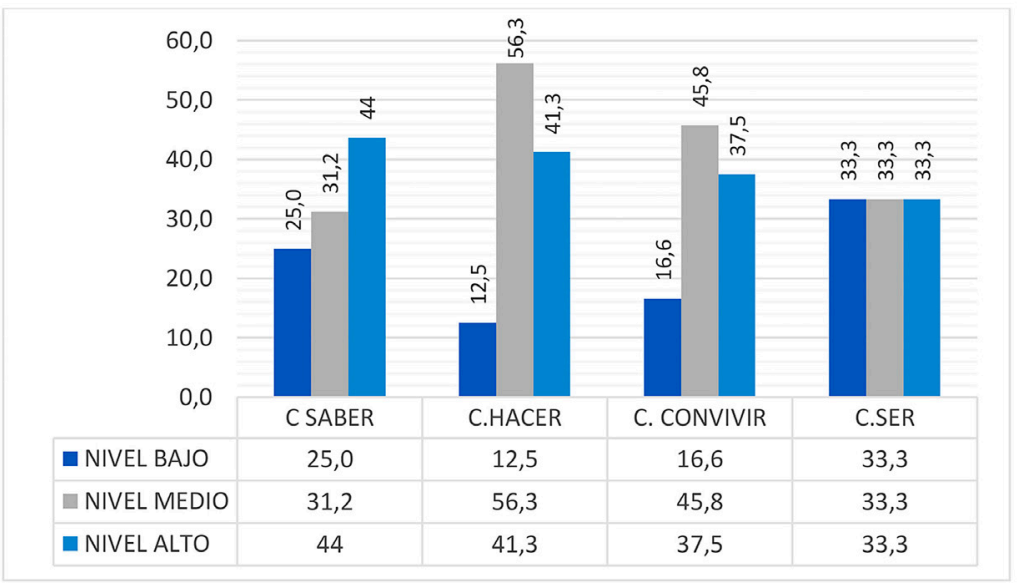

Figura 4. Competencias de género en el Área de Formación Investigativa Fuente: Elaboración propia

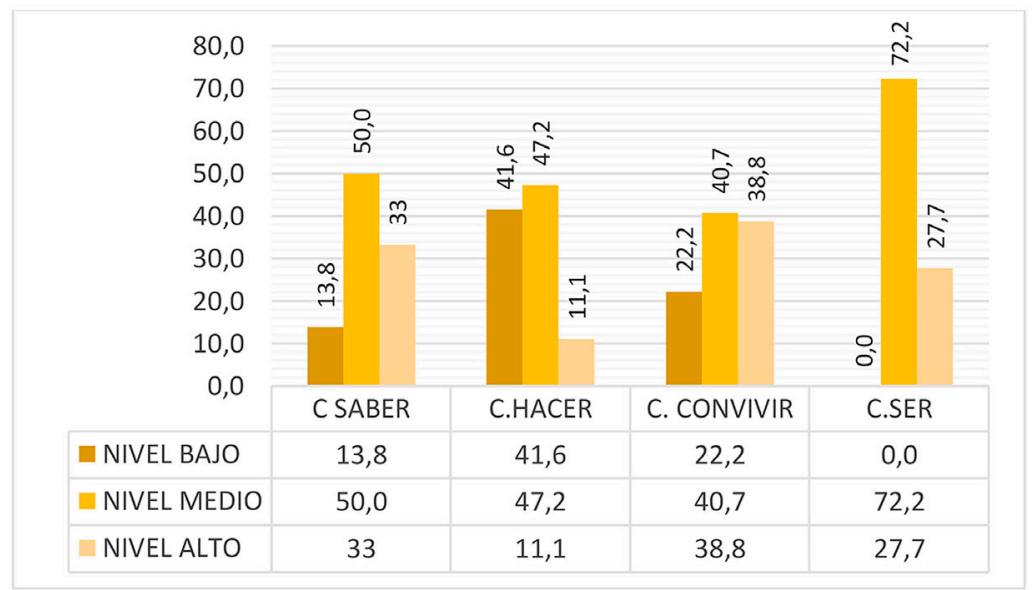

Figura 5. Competencias de género en el Área de Formación Sociohumanística Fuente: Elaboración propia 


\section{Resultados del modelo TSS por áreas de formación}

Los resultados que se muestran a continuación hacen parte de la evaluación propuesta en el modelo TSS, en la que se tienen en cuenta los objetivos, el contexto, los procesos y los resultados de cada una de las propuestas académicas de las áreas de formación. Así, a partir del análisis de las entrevistas de los cuatro docentes coordinadores de las áreas, se presenta la síntesis dentro de matrices de evaluación cualitativa, teniendo en cuenta la exploración de la construcción académica y curricular del área dentro del programa de Ciencias Militares en cuanto a las competencias de igualdad de género.

La tabla 4 analiza la matriz de evaluación del área básica. Desde allí se deduce que dentro de los objetivos educativos del área, el análisis del contexto educativo, los procesos por los que se construye el quehacer educativo y los resultados de este no están tomando en cuenta las competencias de igualdad de género. Esto hace que el planteamiento curricular se simplifique en estereotipos de género que condicionan el desarrollo humano en direcciones restrictivas que promueven construcciones culturales arbitrarias y convencionales.

Tabla 4. Matriz TSS de evaluación del Área Básica

\begin{tabular}{cl}
\hline Criterio & \multicolumn{1}{c}{ Valoración } \\
\hline \multirow{3}{*}{ Objetivos } & $\begin{array}{l}\text { Los objetivos que se definen en el área no contemplan el enfoque de género } \\
\text { dentro de su propuesta curricular. } \\
\text { Si bien se plantean situaciones y condiciones que garantizan los objetivos de } \\
\text { los saberes y del área, en estas no se aplican las competencias de género en } \\
\\
\text { sus propósitos y objetivos educativos. } \\
\\
\text { Dentro del área básica se entiende y se contempla el contexto educativo } \\
\text { militar, en el que se hace el ejercicio aplicable a la realidad del estudiante, } \\
\text { sin embargo, este contexto no toma en cuenta las competencias de igualdad } \\
\text { de género. } \\
\text { Se encuentra en la evaluación, como necesidad, que el estudiante realice } \\
\text { ejercicios prácticos en los que disgregue datos por género, en el caso de } \\
\text { Estadística, y logre comenzar a acercarse a estudios y categorizaciones que } \\
\text { lo lleven a interpretar la igualdad en su contexto. Así, los intereses en el } \\
\text { área respecto a la transversalización del enfoque de género coadyuvan al } \\
\text { estudiante a desarrollar un pensamiento práctico e inclusivo que contemple } \\
\text { todos los posibles escenarios de estudio. }\end{array}$ \\
\hline
\end{tabular}




\begin{tabular}{|c|c|}
\hline Criterio & Valoración \\
\hline Contexto & $\begin{array}{l}\text { Finalmente, las exigencias comprenden el trabajo práctico con didácticas } \\
\text { que implican la resolución de problemas básicos, con una visión del ser } \\
\text { humano integral, inclusiva y con respeto por el otro, a partir de las eviden- } \\
\text { cias de las ciencias formales. }\end{array}$ \\
\hline Proceso & $\begin{array}{l}\text { Las actividades, métodos, estrategias y técnicas aplicables al proceso de } \\
\text { formación en el área no contemplan estudios de género, ni informes que } \\
\text { lleven al estudiante a la presentación de resultados que tengan en cuenta } \\
\text { esta categoría. } \\
\text { En cuanto a la determinación de recursos, se evidencia que no se contempla } \\
\text { un plan de acción para la inclusión del enfoque de género dentro de los } \\
\text { saberes del área de formación básica. Esto denota que se le da poca impor- } \\
\text { tancia a la creación de mecanismos que acerquen a los estudiantes al análisis } \\
\text { de las diferencias y a la compresión de la diversidad. }\end{array}$ \\
\hline Resultados & $\begin{array}{l}\text { Logros alcanzados: se habla de competencias del ser y del convivir, en las que } \\
\text { se tiene una orientación que se aproxima a la transversalización del enfoque } \\
\text { de género. } \\
\text { Evaluación: el enfoque de género no está incluido en la propuesta académica } \\
\text { del programa. } \\
\text { Intercambio de experiencias: se informa de estudios y casos en universidades } \\
\text { como la de Estocolmo, donde las carreras en las que se encuentran áreas de } \\
\text { formación básica incluyen el enfoque de género no solo para el análisis de } \\
\text { datos, sino para evitar la estereotipación en las carreras (por ejemplo, que las } \\
\text { ingenierías son para hombres). }\end{array}$ \\
\hline
\end{tabular}

Fuente: Elaboración propia

El análisis del Área de Formación Profesional General se presenta en la tabla 5. Es importante tener en cuenta que la propuesta académica del área es extensa debido a que contiene un gran número de materias. Los hallazgos muestran un área interdisciplinar en la que se condensa un currículo con una perspectiva masculina de lo social. Esto quiere decir que los objetivos educativos, el contexto, los procesos y los resultados se inclinan a la formación de un modelo militar masculino único, que regula la educación militar de hombres y mujeres. No se evidencia, por tanto, una crítica reflexiva de las creencias, actitudes y valores que promuevan la transformación de roles, la inclusión de una perspectiva de género, y la elevación del valor del papel femenino en el ámbito militar. 
Tabla 5. Matriz de evaluación del Área de Formación Profesional General

\begin{tabular}{|c|c|}
\hline Criterio & Valoración \\
\hline Objetivos & $\begin{array}{l}\text { Los objetivos que se definen en el área no contemplan el enfoque de género } \\
\text { dentro de su propuesta curricular. } \\
\text { Dentro del planteamiento de los objetivos educativos en el área, no se } \\
\text { evidencia la incorporación de competencias de igualdad de género, puesto } \\
\text { que no se establece la ejecución de un rol específico para la mujer; tampoco } \\
\text { se evidencia que esto sea un aspecto importante para el propósito del } \\
\text { programa. }\end{array}$ \\
\hline Contexto & $\begin{array}{l}\text { En el área se contempla el contexto educativo militar, en el que se hacen ejer- } \\
\text { cicios aplicables a la realidad del estudiante, puesto que se encuentran materias } \\
\text { que tienen que ver con la vida militar, como Procesos Disciplinares, Doctrina } \\
\text { Militar y Procesos de Inteligencia. Para esto se cuenta con docentes que no } \\
\text { solo tienen el conocimiento, sino también experiencia, puesto que muchos }\end{array}$ \\
\hline Contexto & $\begin{array}{l}\text { son docentes militares activos o que se encuentran retirados. Sin embargo, } \\
\text { al determinar las necesidades educativas de los estudiantes no se contemplan } \\
\text { las competencias de igualdad de género, principalmente, en lo que tiene que } \\
\text { ver con el saber estar, es decir, la participación y las competencias del ser, ya } \\
\text { que se incurre fácilmente en esencialismos genéricos. Finalmente, aunque } \\
\text { existen saberes que exploran los derechos humanos, el ámbito jurídico y la } \\
\text { acción integral, la formación en ellos no garantiza la transversalización de } \\
\text { género, puesto que el contexto no reconoce las situaciones y vivencias de } \\
\text { mujeres y hombres en diferentes escenarios de la cultura militar. }\end{array}$ \\
\hline Proceso & $\begin{array}{l}\text { En cuanto a la descripción de estrategias educativas que el área tiene frente } \\
\text { a la transversalización de género, se observa que existe un plan por cada } \\
\text { saber en el que se determina un sistema de control adecuado del proceso de } \\
\text { formación de los estudiantes. Además, se plantea un mecanismo de control } \\
\text { de este a través del seguimiento por medio de la evaluación continua de } \\
\text { los saberes que conforman el área. Respecto a las competencias de igualdad } \\
\text { de género, la aplicabilidad de estas no alcanza a ser propositiva para poner } \\
\text { en marcha actitudes sensibilizadoras que promuevan en la institución la } \\
\text { equidad e igualdad. }\end{array}$ \\
\hline Resultados & $\begin{array}{l}\text { A partir de lo anterior, el resultado no evidencia un alto grado de inter- } \\
\text { cambio de experiencias frente a lo que se espera de la transversalización de } \\
\text { las competencias de igualdad de género y tampoco se observa en la evalua- } \\
\text { ción una metaevaluación constructiva al respecto. } \\
\text { Intercambio de experiencias: se comenta sobre los casos de academias mili- } \\
\text { tares como la de Chile, Francia y Espańa, en las que dentro de sus programas } \\
\text { académicos se incorpora el enfoque de género y se adelantan estudios inves- } \\
\text { tigativos sobre asuntos de género. }\end{array}$ \\
\hline
\end{tabular}


La tabla 6 muestra los resultados de la evaluación del Área de Formación Investigativa. Se analiza que, en comparación con las demás áreas de formación, en esta se incluyen los proyectos de investigación en asuntos de género como una estrategia dentro de los procesos educativos para fomentar la transversalización de las competencias de igualdad de género, lo cual es una ventaja para este fin. Los análisis evidencian que el contexto y los objetivos de la propuesta académica del área no toman en cuenta las diferencias entre hombres y mujeres, lo cual se piensa como igualdad, pero en realidad es una falta de equiparación de oportunidades y da lugar a la ocupación de posiciones asimétricas en la formación profesional. Esto último se observa de manera general en todas las áreas de formación del programa.

Tabla 6. Matriz de evaluación del Área de Formación Investigativa

\begin{tabular}{cl}
\hline Criterio & \multicolumn{1}{c}{ Valoración } \\
\hline \multirow{3}{*}{ Objetivos } & $\begin{array}{l}\text { El área de Formación Investigativa presenta claridad en el planteamiento } \\
\text { de objetivos educativos y determina la forma de conseguirlos. Respecto a la } \\
\text { transversalización del enfoque de género, los objetivos no aclaran de manera } \\
\text { específica el alcance de una implementación de competencias en el tema. }\end{array}$ \\
& Al igual que las áreas anteriores, el Área de Investigación plantea el contexto \\
Contexto & $\begin{array}{l}\text { específico de la institución y, a partir de los seguimientos que se hacen } \\
\text { dentro del Área, se establecen las necesidades educativas, los valores y las } \\
\text { exigencias respecto a la formación en investigación de los estudiantes; pero } \\
\text { Proceso } \\
\text { hombres y mujeres. }\end{array}$ \\
& $\begin{array}{l}\text { Las estrategias usadas en el área para el logro de la transversalización de } \\
\text { género comprenden estudios de investigación formal y formativa, que se } \\
\text { centran en aportar e impulsar propuestas en pro de la igualdad de género } \\
\text { en diferentes áreas de la institución. También se evidencia la búsqueda de } \\
\text { soluciones a partir de los procesos investigativos con el fin de resolver las } \\
\text { rivalidades de género de la institución. }\end{array}$ \\
& $\begin{array}{l}\text { La transversalización dentro de esta área de formación se evidencia al } \\
\text { encontrar estudiantes y profesores que investigan sobre asuntos de género. } \\
\text { Además, dentro de sus syllabus académicos comprende la importancia que } \\
\text { tiene, en los diseńos metodológicos de las investigaciones, conocer y usar } \\
\text { herramientas analíticas para la aplicación de la transversalidad de género. }\end{array}$ \\
\hline
\end{tabular}

Fuente: Elaboración propia 
Por último, la tabla 7 presenta la matriz de evaluación del Área de Formación Sociohumanística. El análisis de la propuesta académica muestra algunas materias que proyectan dentro de sus objetivos educativos y procesos la formación de estudiantes con un sentido social, con respeto por las diferencias y la inclusión. Es la única área de formación que plantea desde los contenidos académicos la violencia de género, los derechos sexuales y reproductivos y el enfoque diferencial en la Fuerza, entre otros. En cuanto al contexto, al igual que en las otras áreas de formación, este aspecto resulta ser una desventaja para la transversalización de las competencias de igualdad de género, porque no se evidencian aspectos que estructuren desde lo social las relaciones entre hombres y mujeres para la construcción de una identidad profesional femenina y masculina.

Tabla 7. Matriz de evaluación del Área de Formación Sociohumanística

\begin{tabular}{|c|c|}
\hline Criterio & Valoración \\
\hline Objetivos & $\begin{array}{l}\text { Los objetivos del área de Formación Sociohumanística contemplan las } \\
\text { competencias de igualdad de género: derechos humanos, derecho interna- } \\
\text { cional humanitario, psicología y psicología militar. Esto indica que existe } \\
\text { una ruta y estrategia clara para alcanzar el logro de los objetivos y dar cuenta } \\
\text { de la transversalización de género en la institución. }\end{array}$ \\
\hline Contexto & $\begin{array}{l}\text { Al ser un área que incluye las ciencias sociales y humanas, comprende dentro } \\
\text { del análisis del contexto educativo la importancia del enfoque de género } \\
\text { como proceso de promoción de la cultura de igualdad y equidad. Aunque } \\
\text { no lo hace de manera clara y específica, plantea dentro de sus propuestas } \\
\text { curriculares necesidades, intereses y exigencias que determinan el comienzo } \\
\text { del esfuerzo de la institución por incorporar la transversalización de las } \\
\text { competencias de igualdad de género en el programa académico de Ciencias } \\
\text { Militares. }\end{array}$ \\
\hline Proceso & $\begin{array}{l}\text { Las estrategias y técnicas que aplican al proceso de formación para el logro de } \\
\text { la transversalización dentro del área son la inclusión de temas en los conte- } \\
\text { nidos académicos sobre el enfoque de género, el manejo de las violencias de } \\
\text { género y la elaboración de proyectos de vida incluyentes que promueven la } \\
\text { igualdad y la equidad. }\end{array}$ \\
\hline Resultados & $\begin{array}{l}\text { Los resultados de la transversalización en esta área son positivos en cuanto } \\
\text { a la aplicación de competencias de igualdad de género. En efecto, se reco- } \\
\text { nocen materias de aprendizaje relacionadas con el género, que determinan } \\
\text { un cambio actitudinal y profesional del ser, pues vinculan la integración del } \\
\text { enfoque de género con el quehacer cotidiano y la vida diaria. }\end{array}$ \\
\hline
\end{tabular}




\section{Discusión}

La transversalización o mainstreaming no solo implica la movilización de esfuerzos desde lo político para la promoción de la igualdad como principio y como valor social, sino que también es un proceso técnico que requiere el diseño y evaluación de cambios en las culturas institucionales y la unificación de políticas para conseguir que se haga real dentro de todos los niveles y se tomen decisiones por parte de la institución. Este proceso resulta importante desde la planificación y diseño de los programas académicos, dentro de los cuales están los recursos, las políticas, los procesos de asesoría y orientación, las metodologías y los objetivos en cada propuesta curricular.

Los resultados expuestos anteriormente dejan como tema de discusión los estereotipos en el fundamento de un contexto educativo militar y la educación para la igualdad. $\mathrm{Al}$ respecto, se reconoce que los estereotipos se orientan por los modelos impuestos a cada sexo y que, de alguna manera, determinan su comportamiento y ajuste a lo social, es decir, limitan el conocimiento de la diversidad, la complejidad de los grupos y la variaciones individuales. Estos estereotipos acompañan a cada ser humano desde que nace, así que no es una condición netamente institucional, por tanto, lo comparten directivas, docentes y estudiantes en su diario vivir. Tal como lo muestran los resultados de este estudio, los docentes del programa de Ciencias Militares diseñan currículos estereotipados, que condicionan y orientan el desarrollo humano de forma restrictiva en un contexto educativo marcado por una cultura masculina propia de los ejércitos (perspectiva masculina de lo social). Esto genera relaciones de poder entre hombres y mujeres que inevitablemente desembocan en rivalidad sexual, insatisfacción laboral y currículos con manifestaciones irreales de la vida social actual.

Este análisis muestra la necesidad de que se incorpore en los currículos la perspectiva de los fenómenos sociales integrales y la formación de los docentes para estimular la reflexión crítica sobre las creencias, los valores y las actitudes respecto a la perspectiva de género en la institución.

Las áreas que más necesitan de este cambio en el programa de Ciencias Militares son las de Formación Básica y Formación Profesional General. En estas se deben ver reflejadas las propuestas académicas dinámicas, contextualizadas y que tengan en cuentan procesos de transformación tanto de profesores como de estudiantes, para generar prácticas educativas que eliminen el trato discriminatorio y promuevan la igualdad y la equidad. Así mismo, deben contener objetivos educativos que acerquen al estudiante a la internalización del enfoque de género a partir 
del reconocimiento de diferencias en las situaciones que viven tanto hombres como mujeres dentro del contexto militar y que construyan una transversalización en pro de una libertad y justicia igualitarias.

La educación para la igualdad es otro tema que tiene aspectos importantes para la discusión en el presente estudio. Al respecto la misión de educar en la igualdad implica transformar los criterios de las prácticas educativas y de las propias actitudes de los docentes, de tal manera que se analicen y se cambien los objetivos educativos, los procesos, las didácticas y metodologías que reposan en la propuesta curricular.

La evidente debilidad que muestran los resultados de la evaluación de las competencias de igualdad de género lleva a entender que en el plano sociocultural —es decir, en la dimensión del saber (conocimientos en cuanto a género)—, la transversalización implica reconocer las situaciones que viven tanto hombres como mujeres en los diferentes contextos culturales e institucionales, con el fin de combatir los esquemas de rivalidad entre sexos y promover el reconocimiento del papel de la mujer dentro de la Fuerza.

En cuanto al plano relacional (dimensión del convivir), los análisis determinan que se debe abordar desde las metodologías en clase el afianzamiento de competencias que permitan al estudiante contextualizar los conocimientos de interacción social entre hombres y mujeres adquiridos desde sus experiencias individuales, con la finalidad de promover medidas orientadas a eliminar modelos tradicionales de roles femeninos y masculinos. De esta forma, podrán asumir modelos de género construidos en ambientes determinados, para comprender, adaptarse, enfrentarse y resolver situaciones de desigualdad en distintos escenarios culturales.

Por último, en el plano personal, se deben propiciar espacios en los que se reconozca un cambio actitudinal y profesional desde el mismo individuo y que se vincule a la integración del enfoque de género en las actividades diarias.

\section{Conclusiones}

Con la evaluación del programa, se determinó si los objetivos educativos propuestos y los resultados que se tienen hasta ahora son coherentes y apuntan a la integración del enfoque de género en la institución. De igual forma, se determinó la coherencia entre el modelo curricular de la institución y los objetivos que se tienen en cuanto a la transversalización de la igualdad de género. El resultado de la evaluación permitió ver si se han propuesto las estrategias, técnicas y actividades acordes con el contexto educativo militar y si estas han dado respuesta a las necesidades e intereses de formación de hombres y mujeres. 
Es importante que se incorporen objetivos específicos en cuanto al enfoque de género dentro de las propuestas académicas de las áreas de formación del programa que lleven al reconocimiento de la igualdad efectiva en derechos de mujeres y hombres, así como a la solución y gestión eficaz de los conflictos por causa del género.

Otro aspecto que es importante que se tome en cuenta dentro del proceso académico y educativo es la capacitación y formación de los docentes para el análisis crítico de los propios prejuicios y de su entorno en cuestiones de género. De esta manera, se consigue promover efectivamente el principio de igualdad a partir de la confrontación de los estereotipos tradicionales y la construcción actual de nuevos feminismos y nuevas masculinidades.

Finalmente el estudio concluye que el proceso de formación de la ESMIC no tiene diferencias para mujeres y hombres. Esto quiere decir que ambos reciben las mismas materias e intensidad académica, sin tener en cuenta las diferencias biológicas, académicas y contextuales, por lo cual valdría la pena revisar si dentro del plan carrera propuesto, una vez se asciende al grado subteniente, se tiene el mismo índice de igualdad de oportunidades para el desempeño de las labores.

\section{Referencias}

Araya, S. (2002). Las representaciones sociales: ejes teóricos para su discusión. Facultad Latinoamericana de Ciencias Sociales.

Asián, R., Cabeza, F., \& Rodríguez, V. (2014). Formación en género en la Universidad: ¿̨materia de asignaturas específicas o de educación transversal? Revista Historia de la Educación Latinoamérica, 17(24), 35-54. https://doi.org/10.19053/01227238.3310

Bas-Peña, E., Ferre, E., \& Maurandi-López, A. (2017). Educación superior, competencias transversales y género: validación de un instrumento. Revista de Humanidades, 31, 57-76.

Beauvoir, S. (1949). The second sex. Vintage Books.

Bergold, S., Went , H., Kasper, D., \& Steinmayr, R. (2017). Academic competencies: Their interrelatedness and gender differences at their high end. Journal of Educational Psychology, 109(3), 439-449.

Bourdieu, P. (2000). La dominación masculina. Anagrama.

Bunk, G. (1994). La transmisión de las competencias en la formación y perfeccionamiento profesional en la FFA. Cedefor.

Buxarrais, M . (2008). La perspectiva de género en los currícula: hacia la igualdad en la educación. En P. Aznar, \& P. Cánovas (Eds.), Educación, género y politicas de igualdad. Universidad de Valencia.

Colás, P. (2007). La construcción de la identidad de género: enfoques teóricos para fundamentar la intervención educativa. Revista de Investigación Educativa, 25(1), 151-166. http://revistas. um.es/rie/article/view/96661/92871 
Constenla, J. (2007). Los enfoques actuales de la evaluación y sus implicancias en la práctica en el aula. Chile.

Durán, M. (2012). La transversalidad de género en la educación superior: propuesta de un modelo de implementación. Revista Posgrado y Sociedad, 12(1), 23-43.

Escorcia, R., Gutiérrez, A., \& Henríquez, H. (2007). La educación superior frente a las tendencias sociales del contexto. Educación y Educadores, 10(1), 63-77.

Escuela Militar de Cadetes "General José María Córdova”. (2015). Proyecto Educativo del Programa Profesional en Ciencias Militares. Bogotá.

Fernández, A., \& Latorre, E. (2018). Perfil sociodemográfico de los futuros oficiales del Ejército Nacional de Colombia. En A. Fernández, \& E. Latorre (Eds.), La construcción del rol de la mujer militar (pp. 13-39). Escuela Militar de Cadetes "General José María Córdova".

Hoy, W., \& Miskel, C. (2014). Educational administration: Theory, research, and practice. McGraw-Hill.

Latorre, E. J. (2017). Desarrollo de la cultura de la investigación en jóvenes docentes oficiales del Ejército Nacional de la Escuela Militar: una propuesta curricular. Bogotá.

Lattuada, M. (2014).La evaluación de la investigación en las universidades argentinas. Contextos, culturas y limitaciones. CTS: Revista Iberoamericana de Ciencia, Tecnología y Sociedad, 9(27), 157-164.

Mimbrero, C. (2014). Nuevo modelo diagnóstico de la cultura de género en la administración local y en el tercer sector social de acción local. Universidad de Sevilla.

Ministerio de Defensa Nacional. (2010). Lineamientos curriculares de las Fuerzas Militares. Bogotá.

Scriven, M. (1967). The methodology of evaluation. Indiana University.

Stolke, V. (2004). la mujer es puro cuento: la cultura del género. Estudios Feministas, 2(12), 77-105. http://www.scielo.br/pdf/ref/v12n2/23961.pdf

Stufflebeam, D., \& Shinkfield, A. (1987). Evaluación sistemática: guía teórica y práctica. Paidos.

Surovikina, E. (2015). Aproximaciones sistémicas a la gestión educativa: un estado del arte desde la perspectiva de género. Revista Iberoamericana de Educación, 67, 121-138. https://doi. org/10.35362/rie670221

Tyler, R. (1973). Principios básicos del currículo. Editorial Troquel.

Wertsch, J. V. (1991). Voices of the mind: A sociocultural approach to mediated action. Harvard University Press. 